DOI 10.37882/2500-3682.2021.04.18

\title{
ЧЕТЫРЕ ИЗМЕРЕНИЯ МАТЕРИНСКОЙ СЕПАРАЦИИ ВНУТРИ РАЗНЫХ СЕПАРАЦИОННЫХ КОНТЕКСТОВ В ЖИЗНИ МАТЕРИ
}

\section{FOUR DIMENSIONS OF MATERNAL SEPARATION WITHIN DIFFERENT SEPARATION CONTEXTS IN THE MOTHER'S LIFE}

\section{E. Sorokina}

Summary: Traditionally, the concept of separation is considered in the context of the process of forming the child's personality and gaining autonomy from the mother. However, the phenomenon of separation is not limited to the child-parent context: the author considers maternal separation an equally significant problem that requires attention of the psychological science, and far from understanding the latter just as the separation of the mother from the child, points out several other important aspects in it. These are different contexts of maternal separation, depending on the object from which the separation occurs. And these are also four dimensions that the separation process goes through: physical, emotional, cognitive and spiritual. The article examines each of the dimensions of the separation process in terms of different separation contexts, and also draws conclusions about the relationship and interactions of separation contexts and dimensions.

Keywords: motherhood, mothering, separation, separation process, child-parental separation, child-mother separation, maternal separation, objects of maternal separation, separation context, object of separation, maternal myth, dimensions of maternal separation, physical separation, emotional separation, cognitive separation, spiritual separation.

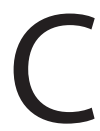

епарация - тема, актуальная в сфере помогающих практик: детские педагоги и психологи изучают се-

парационные кризисы, рассказывают о процессе сепарации и особенностях прохождения ее отдельных этапов родителям. Этапы прохождения ребенком сепарации в отечественной науке описываются в рамках концепций периодизации развития и возрастных кризисов (Л.И. Божович [2], А.Я. Варга [4], Л.С. Выготский [6], Т.В. Драгунова [8], А.Н. Леонтьев [12], Л.Ф. Обухова [16], К.Н. Поливанова [17], В.И. Слободчиков [18], Л.В. Сысоева [19], Д.Б. Эльконин [23]).

При этом то, что сепарационный процесс имеет, фактически, две стороны - не только сепарация ребенка от матери, но и сепарация матери от ребенка (или, в широком смысле, - детско-родительская и родительско-детская сепарация) - нередко оказывается за пределами фокуса внимания теоретиков и практиков.

Так, исследователи говорят о психологической се-

\author{
Сорокина Екатерина Николаевна \\ К.п.н., Институт Психологии Творчества, \\ Нижний Новгород \\ grinrys@yandex.ru
}

Аннотация: Традиционно понятие сепарации рассматривается в контексте процесса формирования личности ребенка и обретения им все большей автономии от матери. Однако феномен сепарации не ограничивается детско-родительским контекстом: не менее значимой проблемой, требующей рассмотрения в русле психологической науки, автор считает материнскую сепарацию, и не ограничиваясь пониманием последней как только сепарации матери от ребенка, выделяет в ней и другие значимые аспекты. Во-первых, это различные контексты материнской сепарации в зависимости от объекта, от которого происходит сепарация. Кроме того, это четыре измерения, которые проходит сепарационный процесс: физическое, эмоциональное, когнитивное, духовное. В статье подробно рассматривается каждое из измерений сепарационного процесса с точки зрения различных контекстов сепарации, а также делаются выводы о соотношениях и взаимодействии контекстов и измерений сепарации.

Ключевые слова: материнство, материнствование, сепарация, сепарационный процесс, детско-родительская сепарация, детско-материнская сепарация, материнская сепарация, объекты материнской сепарации, сепарационный контекст, контекст сепарации, объект сепарации, материнский миф, измерения материнской сепарации, физическая сепарация, эмоциональная сепарация, когнитивная сепарация, духовная сепарация.

парации (сепарации вообще) за пределами детско-родительского контекста: как о феномене межличностных отношений [7]; изучают механизмы психологической сепарации [22], определяют проблемное поле исследования феномена сепарации [13] и т.д.

Этапы психологической сепарации представлены, преимущественно, в зарубежной психологии, в психоаналитическом направлении через периодизацию развития личности (П. Блос [1], Дж. Боулби [3], Д. Винникот [5], О. Кернберг [9], М. Кляйн [10], М.Х. Кохут [11], Дж. Мак-Девитт [14], М. Малер [15], Б. и Дж. Уайнхолды [20], 3. Фрейд [21], R. Josselsson [24] и др.).

Тем не менее, "материнский", "родительский" аспект сепарационного процесса неразрывно связан с аспектом детской сепарации, и рассмотрение сепарации в единстве двух аспектов - "детском" и "родительском" поможет глубже понять суть и специфику этого процесса, а также позволит родителям и детям успешно проходить 
сепарационные кризисы.

Сепарация в детско-родительском (детско-материнском) аспекте рассматривается, преимущественно, как процесс сепарации-индивидуации ребенка от матери (Дж. Мак-Девитт, М. Малер, Ф. Пайн [14, 15]).

Ниже мы рассмотрим различные сепарационные контексты материнской сепарации, которые мы выделили, исходя из значимых (для процесса сепарации) сфер жизни женщины-матери. Кроме того, мы предлагаем четыре измерения материнской сепарации, представленных внутри каждого контекста, связанного с тем или иным объектом сепарации.

Мы рассматриваем материнскую сепарацию в пяти контекстах, в зависимости от объекта, от которого происходит сепарация. Мы выделяем пять объектов материнской сепарации:

1. От собственной матери;

2. От ребенка;

3. От партнера (мужа);

4. От внешних авторитетов; 5. От объективного и субъективного материнского мифа.

Внутри каждого из представленных пяти контекстов сепарации сепарационный процесс проходит четыре измерения: физическое, эмоциональное, когнитивное, духовное.

Ниже мы рассмотрим четыре измерения сепарационного процесса в жизни матери.

Физическая сепарация. Говоря о физической сепарации, мы подразумеваем физическую эмансипацию женщины (физические действия, такие, как приход или уход, оставление или объединение), происходящую в пяти контекстах, упомянутых выше:

1. От собственной матери: переезд из родительского дома, обретение финансовой независимости (мать утрачивает возможность диктовать дочери свои условия).

2. От ребенка: женщина может расставаться с ребенком, оставляя его няне, в детском саду, в развивающей группе или другом образовательном учреждении.

3. От партнера (мужа): женщина может действовать, исходя из собственных убеждений, а не по решению мужа - пойти с ребенком туда, куда считает нужным, а не туда, куда считает нужным ее партнер.

4. От внешних авторитетов: женщина может выйти из родительской группы, уйти с занятий или лекции эксперта, если это определено ее внутренним выбором, основанным на актуальных ценностях и целях.

5. От объективного и субъективного материнского мифа: женщина может перестать выполнять действия, продиктованные существующим объективным или субъективным мифом (например, выбрать совместный сон или отселить ребенка в собственную кроватку, в соответствии с актуальной системой ее выборов).

Эмоциональная сепарация - сохранение эмоциональной автономии при сохранении уровня эмпатии, невовлечение в эмоциональное поле других людей, способность действовать не под влиянием эмоций, а осознанно, проживая эмоциональный контент ситуации, а не вытесняя и не подавляя его.

Эмоциональная сепарация также, согласно нашей теории, может происходить в пяти контекстах:

1. От собственной матери: отделение собственных чувств от чувств своей матери; выход из чувства вины ("я не виновата в чувствах своей матери"), способность выносить эмоции своей матери, сохраняя собственную систему выборов и связанных с ними действий; способность дифференцировать ответственность с чувством вины; способность отдавать матери ответственность за ее чувства.

2. От ребенка: навык "не заражаться" эмоциями ребенка; способность выдерживать и контейнировать эмоции ребенка; умение распознавать и рефлексировать эмоции - свои и ребенка, отделяя их друг от друга; навык действовать в ответ на эмоции ребенка управляемо, а не рефлекторно.

3. От партнера (мужа): отделение собственных чувств от чувств партнера; выход из чувства вины ("я не виновата в чувствах своего партнера"), способность выносить эмоции партнера, сохраняя собственную систему выборов и связанных с ними действий; способность дифференцировать ответственность с чувством вины; способность отдавать партнеру ответственность за его чувства.

4. От внешних авторитетов: дифференциация когнитивной и эмоциональной сферы, выраженная в способности сохранять эмоциональную стабильность в ответ на мнение авторитета.

5. От объективного и субъективного материнского мифа: способность выносить эмоциональное напряжение, возникающее между структурами субъективного и объективного мифа, без эмоциональных потерь для себя и ребенка, а также без потери позитивного образа себя и ребенка ("с моим ребенком все хорошо, я хорошая мать, несмотря на существующие установки материнского мифа").

Когнитивная сепарация - свобода от мнения другого, способность рассматривать позицию другого, принимать ее, видеть ее право на существование, аргументированность, видеть желания другого, мотивы, цели, сохраняя внутреннюю автономию собственных выборов, желаний, мотивов, целей. Когнитивную сепарацию мы 
также рассматриваем на уровне пяти контекстов:

1. От собственной матери: сохранение позитивных контактов с матерью при сохранении собственного мнения каждой (признание того, что дочь и мать могут иметь разные взгляды на воспитание детей, но сохранять при этом позитивный контекст общения); способность отказывать матери в ее установках относительно материнствования, выстраивая собственное понимание важности того или иного выбора, аргументируя свой материнский выбор для себя самой.

2. От ребенка: понимание того, что ребенок мыслит в своем возрасте иначе, чем я мыслю, как взрослый человек; способность к "переводу с детского языка на взрослый и со взрослого - на детский"; умение объяснять ребенку, учитывая уровень его когнитивного развития.

3. От партнера (мужа): признание за собой права на собственное мнение, отличное от мнения мужа; выдерживать различия во взглядах на воспитание ребенка; понимание того, что у каждого из родителей - своя роль, система убеждений и действий в воспитании ребенка ("мама не должна быть хорошим папой, папа не должен быть хорошей мамой").

4. От внешних авторитетов: узнавая от эксперта новую информацию о родительствовании (воспитании детей), женщина-мать способна, соотнося ее со своим опытом материнствования, думать о прошлой ошибке (и других событиях прошлого), не погружаясь в нее, не строя негативные ожидания от будущего в связи с ней, а осознавая уроки для выстраивания вектора действий, которые приведут к желаемому образу будущего.

5. От объективного и субъективного материнского мифа: способность анализировать субъективный и объективный миф (во всем многообразии его конкретных установок) и переосмысливать их в контексте актуального момента (роста ребенка, изменения внешних обстоятельств, изменения личных целей самой женщины-матери).

Духовная сепарация - рассматривается нами как автономность аксиосферы женщины-матери, ее способность принимать возможные выборы системы ценностей в своей жизни и жизни других людей, выдерживать напряжение этих различий без внутреннего и внешнего конфликта, приводящего к кризису и дезинтеграции как личности самой женщины-матери, ее материнской роли и межличностной коммуникации разных уровней.

1. От собственной матери: способность женщины-матери ставить перед собой вопросы содержания своей материнской миссии, ценностей, реализуемых в материнстве и транслируемых в процессе воспитания ребенку. При этом женщина-мать не сливается с аксиосферой собственной матери как единственно правильной и возможной, но и не строит свою систему ценностей “от противного”, а выбирает собственный вектор материнской миссии.

2. От ребенка: способность говорить с ребенком о ценностной сфере вне жестких директивных установок, но и без страха затрагивать данную тему, без опасения "сказать что-то не то". Экзистенциальные, ценностные вопросы встают перед женщиной-матерью, как правило, когда ребенок начинает их задавать по мере развития своего мышления, вхождения в более широкий социум (средний и старший школьный возраст). Именно в этот момент возникает вопрос о том, насколько женщина-мать готова удерживать свою ценностную систему без попыток подстроиться под аксиосферу ребенка (полное принятие) или авторитарно, категорично влиять на нее (полное неприятие), когда он начинает противопоставлять себя родителям, экспериментировать с "примериванием" разных систем ценностей, ставит под сомнение и подвергает критическому анализу то, что ценно для родителей, сравнивая проповедуемые и исповедуемые ими принципы жизни друг с другом, оценивая, насколько транслируемые ими ценности привели родителей в реальной жизни к удовлетворенности, состоянию счастья, реализации. На этом уровне перед женщиной-матерью встает вопрос готовности принимать своего ребенка в его индивидуальном духовном и ценностном поиске, дать ему право на этот поиск, сохранять с ним близость, доверие, взаимопонимание даже при наличии разного мнения в данных вопросах (к примеру, если ребенок выбирает иную духовную традицию, нежели та, к которой принадлежит мать; если ребенок выбирает свою миссию иначе, чем видит его мать).

3. От партнера (мужа): признание за собой и за партнером права его собственную аксиосферу, на духовное, ценностное развитие в течение жизни, понимание, что этот процесс для каждого может быть динамичным в течение жизни; готовность открыто говорить о ценностной и духовной сфере жизни, не ожидая слияния и тождества в этих вопросах. Кроме того, - признание за партнером паритетного права на участие в формировании аксиосферы ребенка в его воспитании (особенно актуально в случае, если материнское и отцовское представления о воспитании расходятся).

4. От внешних авторитетов: способность формировать, поддерживать и сохранять собственную аксиосферу, духовные принципы жизни и прислушиваться к мнению внешних экспертов и авторитетов без необходимости сливаться либо отрицать их ценностную, духовную базу. К примеру, эксперт рассказывает об этических принципах воспитании ребенка на примере христианских заповедей и, если женщина-мать относится к иной духовной 
традиции, она способна принять близкие ей подходы этики, перенеся их в контекст своей социокультурной, духовной традиции (не отрицая при этом всего предложенного подхода целиком).

5. От объективного и субъективного материнского мифа: способность анализировать субъективный и объективный миф (во всем многообразии его конкретных установок) и переосмысливать их в контексте актуального момента своего развития, своих целей и задач, своих ценностных ориентиров в данный период жизни, осознавать себя в континууме своей жизни как процесса развития, не отрицая собственный путь (в прошлом я была "ужасной" матерью и все делала не так, сейчас я "исправилась"). Принимая тот факт, что в каждой ситуации ее жизненного и материнского пути она делает лучшие из возможных выборов, ценит собственный опыт, принимает те изменения, к которым она приходит, проводя анализ опыта ("ценностью казалось послушание ребенка, я его строго наказывала, чтобы он слушался; теперь я осознаю ценности гуманистического подхода и использую иные методы воспитания вместо наказаний").

Итак, можем сделать следующие выводы:

1. Мы выделяем пять контекстов сепарации (по количеству значимых объектов сепарации и связанных с ними сфер жизни): сепарация от собственной матери, от ребенка, от партнера (мужа), от внешних авторитетов, от объективного и субъективного материнского мифов.

2. Также мы выделяем четыре измерения сепарационного процесса в жизни матери: физическое, эмоциональное, когнитивное, духовное.

3. Внутри каждого измерения сепарационного процесса, в свою очередь, представлены все пять выделенных нами контекстов сепарации.

4. Таким образом, можно говорить об особенностях физической сепарации женщины-матери от ее собственной матери, от ребенка, от партнера (мужа), от внешних авторитетов, от объективного и субъективного материнского мифов. Такое же распределение мы проводим в эмоциональном, когнитивном, духовном измерениях.

5. Перечисленные четыре измерения сепарационного процесса не имеют преемственности; иными словами, физическая сепарация не является условием эмоциональной сепарации, а та, в свою очередь, - условием актуализации когнитивного и духовного измерений сепарации.

6. Каждое из четырех измерений может быть представлено той или иной степенью сепарации. Кроме того, в пяти перечисленных выше контекстах сепарации каждое из четырех измерений также может быть актуализировано в той или иной мере (например, физическая сепарация от матери пройдена, эмоциональная зависимость сохраняется).

\section{ЛИТЕРАТУРА}

1. Блос П. Психоанализ подросткового возраста. - М.: Институт общегуманитарных исследований, 2010. - 272 с.

2. Божович, Л.И. Проблемы формирования личности. Избранные психологические труды / Л.И. Божович. - М.: Воронеж, 2001. - 352 с.

3. Боулби Д. Создание и разрушение эмоциональных связей: Руководство практического психолога / Пер. с англ. В.В. Старовойтова. - М.: «Канон+» РОоИ «Реабилитация», 2014. - 271 с.

4. Варга А.Я. Системная семейная психотерапия. - СПб., 2001. - 187 с.

5. Винникот Д. Маленькие дети и их матери. - М.: «Класс», 1998. - 78 с.

6. Выготский Л.С. Психология развития человека / Л.С. Выготский. - М.: Эксмо-Пресс, 2003. - 1136 с.

7. Дитюк А.А. Психологическая сепарация как феномен межличностных отношений: к проблеме определения понятия // Бюллетень Южноуральского государственного университета. Серия Психология. - 2015. - №8(3). - С. 98-102

8. Драгунова Т.В. Подросток. - М.: Знание, 1976. - 94 с.

9. Кернберг 0.Ф. Отношения любви: норма и патология / Отто Кернберг. - М.: Класс, 2018. - 338 с.

10. Кляйн, М. Развитие в психоанализе / М. Кляйн, С. Айзекс, Дж. Райвери, П. Хайманн. - М.: Академический Проект, 2001. - 512 с.

11. Кохут Х. Анализ самости: Систематический подход к лечению нарциссических нарушений личности. - М.: Когито-Центр, 2017. - 568 с.

12. Леонтьев, А.Н. Избранные психологические произведения / А.Н. Леонтьев. - М.: Педагогика, 1983. - 392 с.

13. Маленова А.Ю. Феномен сепарации: определение проблемного поля исследования / А.Ю. Маленова, Ю.В. Потапова // Вестник Омского университета. Серия: Психология. — 2013. — №2. - С. 41-48

14. Малер М., Мак-Девитт Д. Процесс сепарации-индивидуации и формирование идентичности // Психоаналитическая хрестоматия. Классические труды / ред. М.В. Ромашкевич. - М., 2005. - 360 с.

15. Малер М.С., Пайн Ф., Бергман А. Психологическое рождение человеческого младенца: симбиоз и индивидуация / Пер. с англ. - М.: Когти-Центр, 2011. - 413 с.

16. Обухова Л.Ф. Детская психология: Теория, факты, проблемы. - М.: Тривола, 1998. - 351 с.

17. Поливанова, К.Н. Психология возрастных кризисов / К.Н. Поливанова. - М.: Академия, 2000. - 184 с.

18. Слободчиков В.И. Психология человека: введение в психологию субъективности: учебное пособие / В.И. Слободчиков, Е.И. Исаев. - М.: Изд-во ПСТГУ, 2014. -359 c. 
19. Сысоева Л.В., Петренко Т.В. Проблема сепарации от родителей в русской семье: социокультурный и психологический аспекты // Личность, семья и общество: вопросы педагогики и психологии. - 2016. - № 62. - С. 126-134

20. Уайнхолд Б., Уайнхолд Дж. Освобождение от созависимости. Издание второе, переработанное. / Пер. с англ. А.Г. Чеславской. - М.: Независимая фирма «Класс», 2019. - 364 с.

21. Фрейд 3. Малое собрание сочинений / 3. Фрейд. - СПб.: Азбука, 2014. - 608 с.

22. Харламенкова Н.Е., Кумыкова Е.В., Рубченко А.К. Психологическая сепарация: подходы, проблемы, механизмы. - М.: Изд-во “Институт психологии РАН”, 2015. $-367 c$

23. Эльконин Д.Б. Психическое развитие в детских возрастах: избранные психологические труды / под ред. Д. И. Фельдштейна. - М.: Изд-во Моск. психол.соц. ин-та; Воронеж: МОДЭК, 2001. — 416 с.

24. Josselsson R. Ego development in adolescence. In J. Adelson (Ed.) / R. Josselson. Handbook of Adolescent Psychology. — New York: Wiley, 1980. — P. 188-210.

(с Сорокина Екатерина Николаевна (grinrys@yandex.ru).

Журнал «Современная наука: актуальные проблемы теории и практики» 